\title{
QUANTITATIVE AND \\ QUALITATIVE IMPACT OF \\ GDP ON SPORT PERFORMAN- \\ CE AND ITS RELATION \\ WITH CORRUPTION AND \\ OTHER SOCIAL FACTORS
}

\author{
Impacto cuantitativo y cualitativo del PIB en \\ el rendimiento deportivo y su relación con la \\ corrupción y otros factores sociales
}

Luis Antonio Andrade Rosas ${ }^{1}$, Martin Flegl ${ }^{2}$

Fecha de recepción:13 de febrero 2017

Fecha de aceptación: 02 de mayo 2017

1- Nombre: Luis Antonio Andrade Rosas. Nacionalidad: Mexicana. Grado: Doctorado. Especialización: Economía. Adscripción: Universidad Universidad La Salle México. Correo electrónico: luis.andrade@ulsa.mx

2- Nombre: Martin Flegl. Nacionalidad: Checa, Grado: Doctor. Especialización: Teoría de toma de decisión. Grupo de investigación Análisis de rendimiento y eficiencia de factores sociales, económicos y educativos.Adscripción: Facultad de Negocios, Universidad La Salle México. Correo electrónico: martin.flegl@ulsa.mx 


\section{Abstract}

Summer Olympic Games in Rio 2016 were the biggest and the most important sport event in 2016. Athletes' performance at Olympics is always of a high interest and serve as a basis for analyses. Many countries have started programs of higher sport funding to increase the athletes' performance. A particular example can be Great Britain and its enormous program of sport funding. In this article, we make an econometric analysis of quantitative and qualitative impact of Gross Domestic Product (GDP) on sport performance, with regard to corruption and other social and demographic factors. Our results show that the best explanatory model of the medal ranking in the Summer Olympic Games in Rio 2016 includes qualitative GDP, corruption and Economic Active Population. Therefore, Olympic performan$c e$ is not only explained by the basic population-GDP theory, but there are other social and demographic factors that make the relation complete.

Keywords: Corruption, economic active population, Gross Domestic Product, Olympics, sport performance.

\section{Resumen}

Los Juegos Olímpicos de Verano en Río 2016 fueron el evento deportivo mayor y más importante en 2016. El rendimiento de los atletas en los Juegos Olímpicos siempre es de gran interés y sirven como base para análisis. Muchos países han iniciado programas de mayor financiamiento del deporte para aumentar el rendimiento de atletas. Un ejemplo particular puede ser Gran Bretaña y su enorme programa de financiación deportiva. En este artículo se realiza un análisis econométrico del impacto cuantitativo y cualitativo del Producto Interno Bruto (PIB) sobre el rendimiento deportivo, relacionado con el nivel de corrupción y otros factores sociales y demográficos. Nuestros resultados muestran que el mejor modelo explicativo del ranking de medallas en los Juegos Olímpicos de Verano en Río 2016 incluye PIB cualitativo, corrupción y Población Económicamente Activa. Mostrando con ello, que el rendimiento olímpico, no solo es explicado por la teoría clásica de población-PIB, sino que existen otros factores sociales y demográficos que hacen más completa la relación.

Palabras clave: Corrupción, población económicamente activa, Producto Interno Bruto, Olímpicos, rendimiento deportivo. 


\section{Introduction}

$\mathrm{T}$

he Summer Olympics in Rio 2016 were the biggest and the most important sport event (or a general event) in the year 2016. More than 11,000 athletes from 205 countries (including for the first-time Kosovo, South Sudan, and the Refugee Olympic Team) competed in 306 events in 28 different sports (Rio, 2016). The importance of the Olympics was, for example, reflected by the broadcasting contract, where NBCUniversal had paid USD 4.38 billion for the broadcast rights to the Olympics through 2020 (with an agreement extension from 2021 to 2032 valued at USD 7.65 billion).

The importance of sport event can be measured regarding to several criteria to evaluate its influence. Considering classification developed by Müller (2015), the size and importance of an event are evaluated regarding visitor attractiveness, mediated reach, costs and transformative impact. Then, Summer Olympics are seen as a giga-event with worldwide impact. Successful athletes' (sport) results can lead to higher incomes for national sport federations, as well as higher public attractivity of a particular sport and athletes. The economic benefits of a winning team go beyond just the winning team or athlete. People tend to publicly identify with winning sport teams (End et al., 2002). Consequently, team success can also impact the economy via increased consumption spending as winning has a significant positive impact on real wage income per capita (Davis and End, 2010).

Therefore, sport performance at Olympics is of a high importance. Sport performance at international level is usually measured regarding to level of population and GDP (the traditional population-GDP based theory of Olympic success). These two factors are recognized as the two most important economic and demographic factors (Lozano et al., 2002). In addition, the successful participation at sport event is usually measured by the number of winning medals (Li et al., 2015; Li et al., 2008; Lozano et al., 2002) or by its weighted variation (Wu, 2009). Furthermore, a part of the economic and demographic factors, social factors such as health of population or Index of equality of child survival (Churilow, 2006), or quantitative and qualitative indicators such as quality of opponents, number of gained points or scored goals (Flegl, 2014) are used. The evaluation at a lower level (club level at national leagues) focuses on different set of factors. For example, in football, factors such as shots on and off target, number of tackles, number of goals for and against (Carmichael, Thomas and Ward, 2000), offensive and defensive aspect of the game (Boscá et al., 2009). At the lowest level of players' performance evaluation, factors such as playing time, tackle ratio, or pass completion ratio are used (Tiedemann, Francksen and Latacz-Lohmann, 2011). However, Olympic team size is the best single predictor of the Olympic success (Vagenas and Vlachokyriakou, 2012).

A part of the main economic and demographic factors, other factors are important for sport performance. For example, corrupted environment has negative impact on public sector efficiency and performance (Transparency International, 2016b; Ramírez and Sánchez, 2013). Therefore, level of corruption can be linked to lower performance in sport (Potts, 2014; Masters, 2015). Corruption can have many definitions. Using the commonly accepted standard definition of corruption, established by the World Bank and now used by Transparency International, corruption from the economists' perspective is the abuse of entrusted power for private gain. The existence of corruption behavior appears, in different types, in rich and poor countries in wide variety of areas (health service, education, etc.). What is more, 
corruption in sport itself relates to betting and non-betting issues, and doping, where majority of cases relates to doping (Gorse and Chadwick, 2011).

Moreover, other economic, demographic or social indicators can be used to analyze the sport performance (such as inflation rate, unemployment, number of athletes, etc.). The objective of this article is to analyze and evaluate economic, demographic and social effects related to sport performance and summer Olympic Games in Rio 2016.

The article is organized as follows: Section 1 briefly describes the econometric theory. Section 2 outlines the data and variables employed in this study, whereas section 3 describes the econometric model of this article. Results are presented in section 4 and section 5 offers a discussion over the achieved results.

\section{Methodology}

The main purpose of the article is to apply econometric modelling on relations that exist between results of Olympic Games in Rio 2016 and economic, social and demographic variables. To accomplish this goal, it is necessary to analyze both a functional relationship and a probabilistic analysis of the proposed model. When an econometric analysis is made, and when it is necessary to show the importance

of variables, we must consider two parts: 1) intuitive part reflecting the expected theoretical analysis, and 2) the second part deals with statistical significance that shows the minimal explanatory error of the independent variable over the dependent variable. Regarding the intuitive part, it is necessary to define a correct functional form. On the other hand, the statistical part relates to methodology of hypotheses testing. The main purpose of the presented analysis is theoretical and statistical justification of the proposed econometric models.

\subsection{Functional form: linear and non-linear models}

The simplest representation that captures economic changes of an independent variable with respect to another independent variable, can be expressed as

$$
Q=a+b P, \quad b<0
$$

which shows, how price of a product has a direct impact on the level of individual's purchase $Q$. However, there are more factors that have direct impact on a purchase decision, such as a price of a substitute $\left(P_{S}\right)$, price of a complement $\left(P_{C}\right)$, individual's income $(I)$, taxes $(T)$, etc. If these factors can be controlled, the representation becomes as

$$
Q=a+b P+c P_{S}+d P_{C}+e I+f T
$$


However, it is not necessary that the constructed model is linear. For example, model (1) can be expressed as

$$
Q=A p^{b}, \quad b<0 \text {. }
$$

that capture more real economic situation. Further, we can transform (3) to a linear form, such as

$$
\ln Q=\ln A+b \ln p, \quad b<0
$$

This expression is the same as (1), but the variables are expressed in form of logarithms. Furthermore, coefficient $b$ captures elasticity rather than a slope, i.e. instead of measuring unit impacts the coefficient measures percentage impacts (elasticities). Therefore, if the model consists of more than one variable and model is not linear, then we should express a model in Cobb-Douglas form, such as

$$
W=A X^{b} Y^{c}
$$

Equations of this type can economically show utility functions $W=U(X, Y)$ in terms of two consumed goods and, or as production function $Y=F(X, Y)$, where is capital and is labor. Similarly, as in case of (3), we can linearize this function to obtain

$$
\ln W=\ln A+b \ln X+c \ln Y
$$

which expresses similar form as (2) but with two independent variables and its coefficients as elasticities, i.e. if the original variable was maintained or there was a need to transform it by logarithms or some other expression. For this we must

1. Provide graphical analysis between each independent variable and dependent variable, and see the relation that exists between them, in order to be able to suggest a transformation for all the variables.

2. Know what represents the independent variables as well as the dependent variable, in addition to their domains, to see if any of them need any transformation.

In this article, we work with ii. For example, if represents life expectancy of population, which depends, among other variables, on income level, then we can consider following linear expression

$$
Y=a+b \ln p
$$

where $b$ means that for each percentage increase of income, we get an increase of life expectancy of population. This example shows that because of the dimensions of both dependent and independent 
variables, it is sometimes necessary to use logarithms on some variables to make them more comparable.

Based on the above, the objective is not to start from a functional form that comes from the work, but to infer and compare both the impacts as the relationships between independent and dependent variables and statistically support these impacts.

\subsection{Uncertainty and econometric models}

Apparently, a complete representation, linear or non-lineal, can be constructed. However, not all variables can be observed. There are other variables, such as crisis, strike, war, inflation, etc., which somehow influence the model. Although these variables are somehow known, we cannot control them, as they occur with certain probability. Therefore, these variables are of a random form. Such variables are called disturbances following a known distribution.

Model where disturbances are considered is an econometric model, which representation can be expressed as

$$
W_{i}=a_{0}+a_{1} Y_{1 i}+a_{2} Y_{2 i}+\cdots+a_{k} Y_{k i}+U_{i}
$$

where is a dependent variable, $Y_{1}, Y_{2} \ldots, Y_{k}$ are the observed explicatory variables, is an index referring to number of observations. We consider following assumptions of (8) (Gujarati and Porter, 2004):

1. $U_{i}$ is disturbance variable with a normal distribution with mean 0 and constant variance, so $U_{i} \sim N\left(0, \sigma^{2}\right)$.

2. The $Y_{1}, Y_{2}, \ldots, Y_{k}$ explicatory variables must be uncorrelated, i.e. the explanatory effect must be completely different from the effect $Y_{j}$ for all $i \neq j$.

3. Dependent variable $U_{i}$ must be independent, i.e. if we seek to explain sales of a company in terms of observed variables $Y_{1}, Y_{2}, \ldots, Y_{k}$ then mistakes of a company (such as strike or crisis) should not affect the sales of another company and vice versa.

4. Moreover, these variables $\operatorname{var}\left(U_{i}\right)=\sigma^{2}$ for all $i=1,2, \ldots n$. Such requirement is called homoscedasticity.

The last point is important in the inference analysis of the explanatory variables. For example, the presence of heteroscedasticity is inherited towards the explanatory variable $W_{i}$, which means that $\operatorname{var}\left(\hat{\mathrm{a}}_{i}\right)$ is not fixed (Gujarati and Porter, 2004), provoking that the confidence intervals for the estimated coefficients are not constant. Therefore, distinct significance of $Y_{i}$ over $W_{i}$ would be deduced. It is suggested ${ }^{3}$ a transformation of variables that could have a relative quantity greater than the explanatory variable, such as income, population, etc. The aim of making these relationships more comparable is to avoid greater dispersion of the dependent variable.

In addition, with respect to the interpretive part of (8), the effect of changes of $Y_{1}, Y_{2}, \ldots, Y_{k}$ on $W$ can be expressed as $\frac{\partial W_{i}}{\partial Y_{k i}}=a_{k}$. Further, according to the supposed functional form explained in 1.1, in expres- 
sion (8) both the explanatory or explained variables could have logarithmic o polynomial ( $x^{r}$ where $r \neq 1$ ) transformation. If the transformation of the variables is logarithmic, estimator $a_{i}$ shows

$$
\frac{\partial \ln W_{i}}{\partial \ln Y_{k i}}=a_{k}=\frac{\Delta W / W}{\Delta Y / Y}=\frac{Y}{W} \frac{\Delta W}{\Delta Y}
$$

which represents a percentage effect of $\mathrm{Y}$ over $\mathrm{W}$, which is theoretically called elasticity.

We can estimate values of the coefficients $\mathrm{a}_{\mathrm{j}}(j=1,2, \ldots, k)$ using ordinary least square method (OLS). In this case, we estimate the average behavior of $W_{i}$ given the observations $Y_{1}, Y_{2}, \ldots, Y_{k}$, such as

$$
\widehat{W_{l}}=E\left(W_{i} \mid Y_{1}, Y_{2}, \ldots, Y_{k}\right)=\widehat{a_{0}}+\widehat{a_{1}} Y_{1 i}+\widehat{a_{2}} Y_{2 i}+\cdots+\widehat{a_{k}} Y_{k i}
$$

The explanatory variables in (4) have quantitative character. However, in some cases, it is of a high interest to introduce variables with a qualitative character, such as difference in incomes between genders, different size of country or region. To identify the effects of qualitative variables, we must introduce qualitative variables into an econometric model, such as

$$
W_{i}=a_{0}+a_{1} Y_{1 i}+a_{2} Y_{2 i}+\cdots+a_{k} Y_{k i}+a_{k+1} D_{i}+U_{i}
$$

Where $D$ is a dichotomous variable representing a quality or not. For example,

$$
D_{i}= \begin{cases}1 & \text { if the variable is man } \\ 0 & \text { if the variable is woman }\end{cases}
$$

Thus, if we would like to estimate an average income of a woman, then (11) becomes

$$
\widehat{W_{l}}=E\left(W_{i} \mid Y_{1}, Y_{2}, \ldots, Y_{k} \text { and } D_{i}=0\right)=\widehat{a_{0}}+\widehat{a_{1}} Y_{1 i}+\widehat{a_{2}} Y_{2 i}+\cdots+\widehat{a_{k}} Y_{k i}
$$

where the average income of a woman is . Similarly, if we would like to estimate an average income of a man, then (11) becomes

$$
\widehat{W_{l}}=E\left(W_{i} \mid Y_{1}, Y_{2}, \ldots, Y_{k} \text { and } D_{i}=1\right)=\widehat{a_{0}}+\widehat{a_{k+1}}+\widehat{a_{1}} Y_{1 i}+\widehat{a_{2}} Y_{2 i}+\cdots+\widehat{a_{k}} Y_{k i}
$$

where the average income of a man is $\widehat{a_{0}}+\widehat{a_{k+1}}$.

The qualitative effects can also differentiate the qualitative effects on $W_{i}$ as

$$
W_{i}=a_{0}+a_{1} Y_{1 i}+a_{2} Y_{2 i}+\cdots+a_{k} Y_{k i}+a_{k+1} D_{i} Y_{1 i}+U_{i}
$$

where $D$ is a dichotomous variable as in (11). The difference between (11) and (14) is that in (14) we estimate the effect of $Y_{1 i}$ on $W_{i}$, regarding the character which represents $D_{i}$. In models such as (11) the effects are fixed, whereas in models such as (14) the effects are random. 
Finally, one of the objectives in an econometric model is to have the best model, i.e. to have more variables explicative and significant. However, this inclusion of variables must be statistically justified. Thus, we think in a model with $k$ explicative variables such as

$$
W_{i}=a_{0}+a_{1} Y_{1 i}+a_{2} Y_{2 i}+\cdots+a_{k} Y_{k i}+U_{i}
$$

and suppose that to add $g-k$ variables, getting

$$
W_{i}=a_{0}+a_{1} Y_{1 i}+a_{2} Y_{2 i}+\cdots+a_{k} Y_{k i}+a_{k+1} Y_{k+1 i}+\cdots+a_{g} Y_{g i}+U_{i}
$$

Then, to justify if the aggregation of these new variables is significant, we test the following hypothesis

$$
H_{0}: a_{k+1}=a_{k+2}=\cdots=a_{g+1}=0 \quad \text { vs } \quad H_{0}: a_{i} \neq 0, \quad \text { for any } i=k+1, \ldots, g
$$

To reject $\mathrm{H} \_0$ it is necessary that squared sum of residuals of augmented model $\left(R S S A_{(g)}\right)$ is smaller than squared sum of residuals of the reduced model $\left(R S S A_{(k)}\right)$, and the statistical test is

$$
F_{o b s}=\frac{\operatorname{RSSA}_{(\mathrm{g})}-\operatorname{RSSA}_{(\mathrm{k})} /(k-g)}{\operatorname{RSSA}_{(\mathrm{g})} /(n-g-1)} \sim F_{n-g-1}^{k-g}
$$

So, if $F_{o b s}>F_{n-g-1}^{k-g}$, then we reject $H_{0}$ and, thus, justify that the aggregation is statistically significant.

\section{Data}

In total, 204 nations participated at the Summer Olympic Games in Rio 2016. However, we had to make some corrections due to availability of data. At first, we excluded Independent Olympic Athletes and Refugee Olympic Athletes (both participating in Rio 2016) from the further analysis as they both are not factual countries and, therefore, no economic and demographic data are available.

To express the economic and demographic power of each participated nation, we use GDP in US dollars as the economic indicator, whereas Economic active population (population ages 15-64 as a part of total population) as the demographic indicator. Both indicators were obtained from the World Bank database (World Bank, 2016). GDP and total population are generally considered as the most important factors (Lozano et al., 2002). However, we have chosen Economic active population factor, which better describes nations' potential to generate number of participants to Olympic Games. At Rio 2016, the youngest athlete was 13 years old, whereas the oldest athlete was 61 years old. Thus, economic active population between 15 and 64 years approximately corresponds with the age distribution (although the average age of Olympic athletes is skewed to mean around 25 years old).

At second, we have eliminated following 19 countries due to missing data of either GDP or Econo- 
mic active population: American Samoa, Andorra, Bermuda, British Virgin Islands, Cayman Islands, Chinese Taipei, Cook Islands, Dominica, Liechtenstein, Marshall Islands, Monaco, Nauru, Netherlands Antilles, Palau, Palestine, Saint Kitts \& Nevis, San Marino, Tuvalu, US Virgin Islands. On the other hand, we could find data regarding GDP for North $\mathrm{Korea}^{4}$, and Economic active population for Kosovo ${ }^{5}$.

We use World Bank's classification by income to classify countries per their income (World Bank, 2016) as third factor of the analysis. This factor is treated as dichotomous variable as: 1 - low-income economies (Gross National Income (GNI) per capita of \$1,025 or less), 2 - lower middle-income economies (GNI per capita between \$1,026 and \$4,035), 3 - upper middle-income economies (GNI per capita between $\$ 4,036$ and $\$ 12,475$ ), and 4 - high-income economies (GNI per capita of $\$ 12,476$ or more) $)^{6}$. Further, we use data from World Bank for Inflation rate (INF) as GDP deflator (annual \%).

Further, we use Transparency International (Transparency International, 2016a) Corruption Perception Index (CPI) as a factor describing level of corruption in participated nations at the Olympic Games. The CPI data was not available in case of Belize, Antigua \& Bermuda, Grenada, Solomon Islands, Tonga, and Vanuatu. To keep these countries in the analysis, we extrapolated their CPI considering geographical location: for Belize (31.375) as an average of CPI results of El Salvador, Guatemala, Honduras and Nicaragua; for Antigua \& Bermuda and Grenada (69.556) as an average of Barbados, St. Lucia and St. Vincent \& the Grenadines, and, finally, for Solomon Islands, Tonga and Vanuatu (45.375) as an average of Fiji and Samoa.

Finally, the last factor of the analysis consists of medal ranking. Usually, the analyses of medal ranking consider golden, silver and bronze medal ranking (Li et al., 2008; Wu, Liang, and Yang, 2009). However, to be able to analyze more countries, in this article we consider first 8 place from each discipline. To give higher importance to golden, silver, bronze medals and higher places, we use the IAAF methodology assigning 8pts to golden medal, 7 pts to silver, etc. until 1 pts to 8th place in each discipline. Data were obtained from the official website of Rio 2016 summer Olympic Games (Rio, 2016).

The data covers period from 2011 to 2015, as the length of a preparation for Olympic Games is commonly based on 4-year-long cycles. Moreover, we treat all factors as an average through this period. The data included in this article can be seen in Flegl and Andrade (2016).

\section{Model}

Our variables for constructing the model are as following

- $Y$ - Weighted medal ranking of the first eight positions;

- $X_{1}$ - Gross domestic product (GDP) in US dollars;

- $X_{2}$ - Economic active population (EAP) - population ages $15-64$ as a part of total population;

- $X_{3}$ - Corruption level measured by Corruption Perception Index (CPI) from Trans-

4- Trading Economics. 2016. Available at http://www.tradingeconomics.com/north-korea/gdp (accessed October 15, 2016)

5- Kosovo Agency of Statistics, available at http://ask.rks-gov.net/en/ (accessed October 15, 2016).

6- Detailed methodology is available at: https://datahelpdesk.worldbank.org/knowledgebase/articles/378832-what-is-theworld-bank-atlas-method (accessed October 28, 2016). 
parency International;

- $X_{4}$ - Countries' income classification regarding Gross national income (GNI), treated as dichotomous variable (see (14));

- $X_{5}$ - Inflation rate (INF), GDP deflator (annual \%).

With these variables, our general model is as follows

$$
Y_{i}=\beta_{0}+\beta_{1} \ln X_{1 i}+\beta_{2} \ln X_{2 i}+\beta_{3} X_{3 i}+\beta_{4} D+\beta_{5} X_{5 i}+u_{i}
$$

Models as complete as (18) are difficult to obtain, either by the wrong positive or negative sign of a variable or by the significance of all variables. Therefore, it is advisable to begin with a simple model, such as (1) o (2), and enter the variables one by one, until we reach the best model. This process requires an econometric analysis, which we explain in the next section.

The variables in (18) are of a social character (such as corruption level and countries' income level), as well as of an economic and demographic character (Gross domestic product, economic active population and inflation). We apply log-transformation on some variables to make the magnitude between regressor variables and returned variable as comparable as possible.

\section{Results}

\subsection{Quantitative effect of GDP}

One of the most important variables influencing the medal ranking at Summer Olympics is GDP. Therefore, considering (12), the first model is as follows:

$$
Y_{i}=\beta_{0}+\beta_{1} \ln X_{1 i}+u_{i}
$$

from where we get the following result

$$
\begin{gathered}
\widehat{Y}_{L}=-932.6314+40.7059 \ln X_{1 i} \\
\mathrm{SE}=(96.84) \quad(3.9442) \\
t=(-9.63) \quad(10.32), \quad R^{2}=0.3744, \mathrm{RSS}_{(19)}=2,432,965.44
\end{gathered}
$$

where SE corresponds to standard error of the estimators, $t$ corresponds to values of $t$-test, and RSS refers to residual sum of squares ${ }^{7}$.

We can conclude that the level of GDP is very important to performance at Olympic games, conside-

7- Residuals are nothing more than an estimation of disturbances or errors, and, as the residuals are unknown, an estimation of them is made. 
ring the positive value of $\ln X_{1 i}$. Any country without GDP would have a negative per ${ }^{\mathcal{c}_{-}}{ }_{\overline{1}}{ }^{-\cdots}$ ce (negative coefficient -932.6314), and, thus would not participate at Olympic Games. Given $\overline{\partial \ln X_{1 i}}=40.7059$, a growth of GDP by $1 \%$ would be reflected by a growth in the medal ranking by 40.7059 points. For example, a percentage increase would result in winning 5 golden medals, or in a combination of one bronze medal, 4 times 5th place, three times 6th place, two 7th places and one 8th place.In addition to the achieved results in (19), we can divide analyzed countries into the following four groups considering their Olympic performance (considering the weighted medal ranking):

$$
G= \begin{cases}\text { excellent, } & \text { if } Y \geq 150 \\ \text { good, } & \text { if } 50 \leq Y<150 \\ \text { regular, } & \text { if } 15 \leq Y<50 \\ \text { bad, } & \text { if } Y<15\end{cases}
$$

Considering this division, a country's participation resulting in one bronze medal, one 4th place and two 5th places (19 points in total) can be seen as regular. On the other hand, a country with two golden medals, three silver medals, two bronze medals, and one 4 th position (54 points in total), can be seen with a good performance ${ }^{8}$.

Therefore, a country must reach at least 150 points in the medal ranking to have an efficient participation at the Summer Olympics (Table 1). Considering (19) we get following data

\section{Table 1. Evaluation of group performance level regarding GDP}

\begin{tabular}{|c|c|}
\hline & (in million dollars) \\
\hline 150 & $355,381.000$ \\
\hline 50 & $30,463.8909$ \\
\hline 15 & $12,893.3903$ \\
\hline
\end{tabular}

Thus, a country with GDP lower than 12,893.39 million dollars, is supposed to perform bad at Olympics. Moreover, country with a regular performance would need to increase, in average, its GDP by 2.36 times to have a good performance at the Olympics, and by 27.56 times to reach an excellent performance.

The previous results proved statistical significance of GDP on the medal ranking $(t=10.32)$. However, we can analyze further the significance of GDP and analyze particular cases of countries that have high level GDP and spend significant share of their GDP to sport. For example, Great Britain after Olympic Games in Atlanta 1996 (winning one golden medal and finishing in 36th place in the medal ranking)

8- The levels of performance efficiency are chosen by the authors considering the statistic distribution of the data set, and thus are subjective, but logical. 
began investing more in sport. Before the Summer Olympics in London 2012, Great Britain raised public funding to elite-level sport by $11 \%$ (total funding to sport has increased by $16 \%$ since the Olympics in Beijing 2008). Higher sport funding has led to enormous growth of athlete performance (Table 2). However, this growth has slowed down and, probably, has already reached its upper bound.

\section{Table 2. Ranking of Great Britain in the Olympic Games, 1996-2016}

\begin{tabular}{|c|c|c|c|c|c|}
\hline Olympics & Golden & Silver & Bronze & Total & $\begin{array}{c}\text { Weighted medal } \\
\text { ranking (1st-3rd } \\
\text { position) }\end{array}$ \\
\hline Atlanta 1996 & 1 & 8 & 6 & 15 & 100 \\
\hline Sydney 2000 & 11 & 10 & 7 & 28 & 200 \\
\hline Athens 2004 & 9 & 9 & 12 & 30 & 207 \\
\hline Beijing 2008 & 19 & 13 & 15 & 47 & 333 \\
\hline London 2012 & 29 & 17 & 19 & 65 & 465 \\
\hline Rio 2016 & 27 & 23 & 17 & 67 & 479 \\
\hline
\end{tabular}

In Rio 2016, Great Britain won 2 medals more than in London 2012, resulting in 14 weighted medals more (). Considering the growth of public funding by $11 \%$, it means that a growth of public funding by $1 \%$ resulted in weighted medal growth by 1.2727 . Thus, we can test a hypothesis, whether the increased funding was reflected by the performance in Rio 2016 or not. Therefore, we test following hypothesis

$$
H_{0}: \beta_{1}=1.2727 \text { vs } H_{0}: \beta_{1}<1.2727
$$

Using the confidence level 95\%, $P\left(a<\beta_{1}<b\right)=0.95$, and considering the assumptions of the estimators 9 dimensions for and are:

$$
\begin{aligned}
& \hat{a}=\widehat{\beta_{1}}-\operatorname{se}\left(\beta_{1}\right) 1.96 \\
& \hat{b}=\widehat{\beta_{1}}+\operatorname{se}\left(\beta_{1}\right) 1.96
\end{aligned}
$$

Therefore, the confidence interval according to the data in (20) is $(32.97,48.43)$, which means that the value of does not belong to this interval, and, thus, we can say that is rejected. Great Britain's growth of sport funding was not reflected in higher performance in Rio 2016. On average, each medal at the Rio 2016 has cost GBP 5.5 million (approximately USD 6.95 million). The results of the analysis show decreasing returns to scale of GDP to sport performance. Thus, GDP is not the only important factor that affects the sport performance. Therefore, it is necessary to analyze the effect of other economic, demographic and social factors. 


\subsection{Qualitative and quantitative effect of GDP}

Including variable (GNI) into (17), countries' income classification, we get

$$
Y_{i}=\beta_{0}+\beta_{1} \ln X_{1 i}+\beta_{2} X_{4 i}+u_{i}
$$

The idea is to verify, whether the income classification has an impact on the medal ranking or not. Variable $X_{4}$ represents country's status and, thus, can be expressed as dichotomous variable, as follows:

$$
Y_{i}=\beta_{0}+\beta_{1} \ln X_{1 i}+\beta_{2} D+u_{i}
$$

where

$$
D= \begin{cases}1, & \text { if country belongs to low - income economies } \\ 2, & \text { if country belongs to lower middle }- \text { income economies } \\ 3, & \text { if country belongs to upper middle - income economies } \\ 4, & \text { if country belongs to high - income economies }\end{cases}
$$

using (22) we get the following result

$$
\begin{aligned}
& \widehat{Y}_{l}=-932.8177+40.7264 \ln X_{1 i}-0.1321 D \\
& \mathrm{SE}=(\text { (98.8238) } \\
& t=(-9.44) \quad(9.17) \quad(-0.01), R^{2}=0.3744, \mathrm{RSSA}_{(22)}=2,432,964.01
\end{aligned}
$$

where SE corresponds to standard error of the estimators, $t$ corresponds to values of $t$-test, and RSSA refers to residual sum of squares of the augmented model.

The effect of $\ln X_{1 i}$ is positive and statistically significant ( $\left.t=9.17\right)$. On the other hand, the effect of $D$ is negative and not significant $(\mathrm{t}=-0.01)$. The negative effect of $D$ seems illogical, considering the definition of $D$. Richer country should have better performance and be higher in the weighted medal ranking. However, we can run a test of joint significance:

$$
H_{0}: \beta_{1}=\beta_{2}=0 \quad \text { vs } \quad H_{0}: \beta_{i} \neq 0, \quad \text { for any } i=1,2
$$

We obtain $F_{\mathrm{obs}}^{2.177}=52.96>F_{\mathrm{tab}}^{2.177}=3.047$ resulting in rejection of $\mathrm{H}_{0^{\prime}}$, i.e. the variables together are statistically significant to explain the weighted medal ranking at the Summer Olympic games. Further, as 
we observe variable $D$ as insignificant, then there must some relation between $\ln X_{1}$ and $D$. In this case, the information explained by $D$ is immersed in $\ln X_{1}$, and vice versa. To prove this, we run the following estimation

$$
\ln X_{1 i}=\beta_{0}+\beta_{1} D+u_{i}
$$

and we get the following result

$$
\begin{array}{lll}
\widehat{\ln X_{1 l}}=21.2718+1.3264 D \\
\mathrm{SE}= & (.4902) & (.1948) \\
t= & (43.39) & (6.81), R^{2}=0.2066
\end{array}
$$

High correlation between $\ln X_{1 i}$ and is logical since the status is determined by the income of each country and this is related to the level of GDP ${ }^{10}$.

If we observe a multicollinearity between regressor variables, then the first solution is to separate the impacts, i.e. make a regression only for $\ln X_{1 i}$, as in (14), and make another regression as

$$
Y_{i}=\beta_{0}+\beta_{2} D+u_{i}
$$

from where we get the following result

$$
\begin{aligned}
& \widehat{Y}_{l}=-66.4923+53.8857 D \\
& \mathrm{SE}=(35.1774)(13.9781) \\
& t=(-1.89) \quad(3.86), \quad=0.0771, \mathrm{RSS}_{(24)}=3,589,166.85
\end{aligned}
$$

As a result, in (24) the effect of $D$ on $Y_{i}$ is positive and significant $(t=3.86)$. Thus, the country's status regarding its income is important for performance in sport.

We can conclude that if $D=1$, then we get $\widehat{Y}_{l}=-12.607<0$. In this case, a country ranked as low-income can be expected to gain zero points in the weighted medal ranking. This result goes along with the reality where, in average, the low-income countries perform bad at the Olympics. If $D=2$, we get $\widehat{Y}_{l}=-12.607<0$. Thus, a country ranked as middle-income can expect to gain 41.279 points in the weighted medal ranking (similarly for $\mathrm{D}=3 \rightarrow \widehat{Y}_{l}=95.165$ and $D=4 \rightarrow \widehat{Y}_{l}=149.051$ ).

\subsection{Effect of corruption on medal ranking}

So far, we have analyzed the qualitative and quantitative effect of GDP on the performance at Rio 2016. Furthermore, we can evaluate effect of other variables on the weighted medal ranking. Therefore, we can include level of corruption (CPI) to find out whether there is a statistically significant effect as in the case 
of GDP and GNI. Thus, we include $X_{3}$ into (19) and (24) to measure this significance. We get following expression

$$
Y_{i}=\beta_{0}+\beta_{1} \ln X_{1 i}+\beta_{2} X_{3 i}+u_{i}
$$

and we get the following result

$$
\begin{aligned}
& \widehat{Y}_{L}=-913.0202+38.2765 \ln X_{1 i}+0.9155 X_{3 i} \\
& \mathrm{SE}=\left(\begin{array}{lll}
(96.5596) & (4.0983) & (4.605)
\end{array}\right. \\
& t=(-9.46) \quad(9.34) \quad(1.99), R^{2}=0.388, \operatorname{RSSA}_{(25)}=2,379,825.53
\end{aligned}
$$

Bothvariables GDPand CPI arestatistically significant, incase oflevel of corruption $t_{\mathrm{obs}}=1.99>1.9736=\mathrm{t}_{\text {tab' }}$, which is significant at the confidence level 95\%. Further, we can run a test of joint significance for GDP and level of corruption as following

$$
H_{0}: \beta_{1}=\beta_{2}=0 \quad \text { vs } \quad H_{0}: \beta_{i} \neq 0, \quad \text { for any } i=1,2
$$

We obtain $F_{\mathrm{obs}}^{2.177}=56.12>F_{\mathrm{tab}}^{2.177}=3.047$ resulting in rejection of $H_{0}$, i.e. both variables together are statistically significant to explain the weighted medal ranking at the Rio 2016 Summer Olympic games.

In addition, as $\mathrm{RSSA}_{(25)}=2,379,825.53$ is lower than $\mathrm{RSS}_{(19)}=2,432,965.44$, then the aggregation of level of corruption into the model is statistically significant. And, thus, we get more complete model explaining the performance at Summer Olympics regarding GDP and CPI.

With respect to the achieved results in (25), the effect of corruption on Olympic performance is positive, $\frac{\partial Y_{l}}{\partial X_{3 i}}=0.9155$. Considering the interpretation of CPI (Transparency International, 2016a), the corruption level can vary between 0 and 100 points (the higher the level is, the lower the corruption is). Therefore, every improvement of the CPI by one point, would result in an increase of weighted medal ranking by 0.9155 points. For example, if a country with CPI $=50$ increases its level of corruption by 20 points up to $\mathrm{CPI}=70$, then this country could expect increase in weighted medal ranking by 18.31 points (e.g. 2 more golden medals).Similarly, we can analyze the effect of level of corruption on medal ranking together with countries' income classification (). We analyze following model

$$
Y_{i}=\beta_{0}+\beta_{1} D+\beta_{2} X_{3 i}+u_{i}
$$

with following result

$$
\begin{aligned}
& \widehat{Y}_{l}=-80.9487+32.4144 D+1.518 X_{3 i} \\
& \mathrm{SE}=(35.2383)(16.4502) \quad(.6335) \\
& t=(-2.30) \quad(1.97) \quad(2.40), R^{2}=0.0161, \mathrm{RSSA}_{(26)}=3,476,398
\end{aligned}
$$

Although we got for the countries' income classification $\left(t_{\mathrm{obs}}=1.97<1.9736=t_{\mathrm{tab}}\right)$, we can conclude that 
$D$ is significant at the confidence level of $93 \%$. Moreover, CPI is significant at the confidence level of 95\%. Further, to analyze the joint significance for income classification and level of corruption we test following hypothesis

$$
H_{0}: \beta_{1}=\beta_{2}=0 \quad \text { vs } \quad H_{0}: \beta_{i} \neq 0, \quad \text { for any } i=1,2
$$

We obtain $F_{\mathrm{obs}}^{2.177}=10.50>F_{\mathrm{tab}}^{2.177}=3.047$ resulting in rejection of $H_{0}$, and both variables together are statistically significant to explain the weighted medal ranking at the Summer Olympic games. In addition, as $\operatorname{RSSA}_{(26)}=3,476,398$ is lower than RSS $_{(24)}=3,589,166.85$, then the aggregation of level of corruption into the model is statistically significant. And, thus, we get more complete model explaining the performance at Summer Olympics with regard to country's income classification and the level of corruption.

With respect to the achieved results in (25), the effect of corruption on Olympic performance is positive, $\frac{\partial Y_{l}}{\partial X_{3 i}}=1.518$. Therefore, every improvement of the CPI by one point, would result in an increase of weighted medal ranking by 1.518 points. For example, if a country with CPI=50 increases its level of corruption by 20 points up to $\mathrm{CPI}=70$, then this country could expect increase in weighted medal ranking by 30.36 points (e.g. 2 more golden medals and 2 more silver medals).

\subsection{Effect of economic active population on medal ranking}

Further, we analyze the effect of the economic active population (EAP) level on the weighted medal ranking. Thus, we EAP, $X_{2}$, into (25).

$$
Y_{i}=\beta_{0}+\beta_{1} \ln X_{1 i}+\beta_{2} X_{3 i}+\beta_{3} \ln X_{2 i}+u_{i}
$$

We get the following result

$$
\begin{array}{ll}
\widehat{Y}_{L}=-894.35+28.0735 \ln X_{1 i}+1.5356 X_{3 i} & +13.2018 \ln X_{2 i} \\
t= & (2.88)
\end{array}
$$

Although we get a positive coefficient (13.2018) for EAP, which is logical, this variable is not statistically significant for the medal ranking $\left(t_{\mathrm{obs}}=1.15\right)$. Before eliminating EAP, it might be valuable to propose a combination between GDP and EAP, such as in the following regression

$$
Y_{i}=\beta_{0}+\beta_{1} \frac{X_{1 i}}{X_{2 i}}+\beta_{2} X_{3 i}+u_{i}
$$

where $\beta_{1}$ captures the effect of GDP per capita, in this case per EAP, over the sport performance at the Summer Olympics in Rio 2016. We use GDP per EAP as we seek to measure the performance over po- 
pulation better describing nations' potential to generate number of participants to the Olympic Games. We get the following result

$$
\begin{aligned}
& \widehat{Y}_{L}=18.49+0.00186 \frac{X_{1 i}}{X_{2 i}}+0.169 X_{3 i} \\
& t=\quad(3.18)
\end{aligned}
$$

Although we get a positive coefficient of the GDP per EAP (and significant as $t=3.18$ ), the effect of corruption becomes nonsignificant $(t=0.21)$. Therefore, in this combination we lose significance of corruption on sport performance, which we get in (25).

Moreover, we can also consider the same combination using GDP per EAP in form logarithmic form, as following

$$
Y_{i}=\beta_{0}+\beta_{1} \ln \frac{X_{1 i}}{X_{2 i}}+\beta_{2} X_{3 i}+u_{i}
$$

where $\beta_{1}$ shows the percentage effect of GDP per EAP over sport performance, and the estimation is

$$
\begin{array}{lcc}
\widehat{Y}_{l} & =-292.0484+39.07022 \ln \frac{X_{1 i}}{X_{2 i}}+0.06532 X_{3 i} \\
t & = & (3.41)
\end{array}
$$

Similarly, the effect of corruption in this last regression loses its significance $(t=0.08)$, despite that $\ln \frac{X_{1 i}}{X_{2 i}}$ remains significant $(t=3.41)$. Therefore, we can conclude that any combination between GDP and EAP is not feasible, unless we remove the corruption. However, this is not the purpose of the article, as we would get back to the traditional population-GDP based theory of Olympic success (Lozano et al., 2002).

Fortunately, we have other model that includes both variables, GDP and corruption, in this case of qualitative form (30). Therefore, we add the PEA variable to this model and we have

$$
Y_{i}=\beta_{0}+\beta_{1} D+\beta_{2} X_{3 i}+\beta_{3} \ln X_{2 i}+u_{i}
$$

with following result

$$
\begin{aligned}
& \widehat{Y}_{l}=-779.0623+29.8530 D+2.476 X_{3 i}+42.9026 \ln X_{2 i} \\
& t=
\end{aligned}
$$

In this case, the EAP is statistically significant ( $t=8.83)$, as well as GNI and CPI. Thus, in addition of being intuitive, by the signs of (30), this model is the best, since according to the statistical test (17), we have

$$
F_{\text {obs }}=\frac{3,476,398-2,408,523.53 /(1)}{2,408,523.53 /(176)}=78.033>F_{176}^{1}=3.894
$$




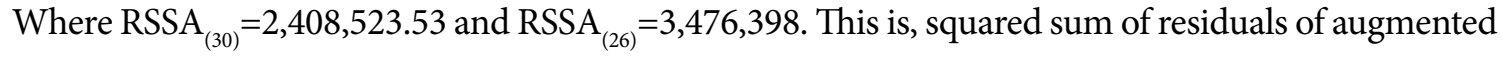
model RSSA ${ }_{(30)}=2,408,523.53$ was significantly reduced.

Therefore, the aggregation of level of EAP makes the model more complete to explain the performance at Summer Olympics, i.e. model (30) represents a relation between the performance at the Summer Olympic Games and economic effects (GNI), demographic effects (EAP) and the corruption (CPI).

It is important to emphasize the way in which the EAP variable enters (30). Although formally does not deduce the functional form to be applied (not the intention of the work), the idea of taking logarithm is to make the regressors of the variable more comparable. Thus, to avoid problems of heteroscedasticity and significance (see section 1.2).

\subsection{Effect of inflation on medal ranking}

Finally, we can analyze the effect of inflation rate on the weighted medal ranking. Thus, we incorporate inflation rate $X_{5}$ into (25)

$$
Y_{i}=\beta_{0}+\beta_{1} \ln X_{1 i}+\beta_{2} X_{3 i}+\beta_{3} X_{5 i}+u_{i}
$$

We get the following result

$$
\begin{array}{lll}
\widehat{Y}_{L}=-914.823+38.1318 \ln X_{1 i}+.9838 X_{3 i}+ & 0.5831 X_{5 i} \\
t= & (9.26)
\end{array}
$$

In this case, INF is not statistically significant for explaining the medal ranking at Olympics $(t=0.51)$. Both variables GDP and CPI are statistically significant, in case of level of corruption $t_{\mathrm{obs}}=2.05>1.9736=\mathrm{t}_{\text {tab }}$, which is significant at the confidence level $95 \%$.

Similarly, we can analyze the effect of inflation rate together with GNI and CPI. We get the following model

$$
Y_{i}=\beta_{0}+\beta_{1} D+\beta_{2} X_{3 i}+\beta_{3} X_{5 i}+u_{i}
$$

We get the following result

$$
\begin{aligned}
& \widehat{Y}_{l}=-98.03705+34.3938 D+1.6513 X_{3 i}+1.6041 X_{5 i} \\
& t=
\end{aligned}
$$

As in model (31), the combination of inflation rate together with GNI and CPI is not statistically significant $(t=1.16)$. 


\section{Discussion}

The most representative model can be considered (30), where the weighted medal ranking is explained by GNI, CPI and EAP. In this case, increase of EAP by $1 \%$ would result in gaining 4.29 in weighted medal ranking, improving corruption level by 1 point would result in 2.476 in weighted medal ranking, and if a country improves in GNI classification (for example from low-income economies to lower middleincome economies), then this country would gain 29.853 points more in weighted medal ranking. Theoretically, this is the most suitable combination how to improve sport performance at Olympic Games.

This result seems logical, as EAP relates to population ages 15-64 as a part of total population. Therefore, this variable describes countries' potential to generate number of participants (athletes) to Olympic Games. As Lozano et al. (2002) point out, GDP and total population are generally considered as the most important factors explaining sport performance (classical population-GDP theory). Nevertheless, economic active population seems better explanatory variable (although high correlation between total population and economic active population is expected). Similarly, income classification gives better explanatory value than GDP.

Result (24) shows that countries ranked as low-income and lower middle-income economies are expected to gain zero points in the weighted medal ranking (result is significant, $t=3.86$ ). This result can be seen in contradiction to result of Athens Summer Olympic games in 2004 performance analysis provided by Li et al. (2008). Li et al. found out that majority of 15 efficient countries ( $24.19 \%$ of total) are from lowincome and lower middle-income economies. In our case, countries of low-income economies gained only $1.43 \%$ of weighted medal ranking, whereas lower middle-income gained $9.43 \%$, upper middleincome $28.19 \%$ and high-income $60.37 \%$ ( $0.58 \%$ belong to eliminated countries from our dataset).

First, it is important to mention that the ranking of GNI classification changes (last time in July 2015). Therefore, some countries from low-income economies are now listed as lower middle-income economies (consequently movements from lower middle-income economies to upper middle-income economies). Second, Li et al. (2008) used different methodology based on Data Envelopment Analysis (DEA) with a different model structure. Model (24) only evaluates the effect of GNI on weighted medal ranking.

Models (25), (26), (27) and (30) indicate positive impact of corruption level on medal ranking. Figure 1 summarizes relation between CPI and Weighted medal ranking regarding GNI classification. We can see that most of the countries of high-income economies have better level of corruption. Moreover, with better level of corruption, these countries achieve better medal ranking. Similarly, countries of upper middle-income economies achieve better medal ranking than lower middle income economies, etc. Therefore, we can conclude that improvement in corruption perception leads to higher probability of achieving better medal ranking. 
Figure 1. Relation between CPI and Weighted medal ranking, GNI classification

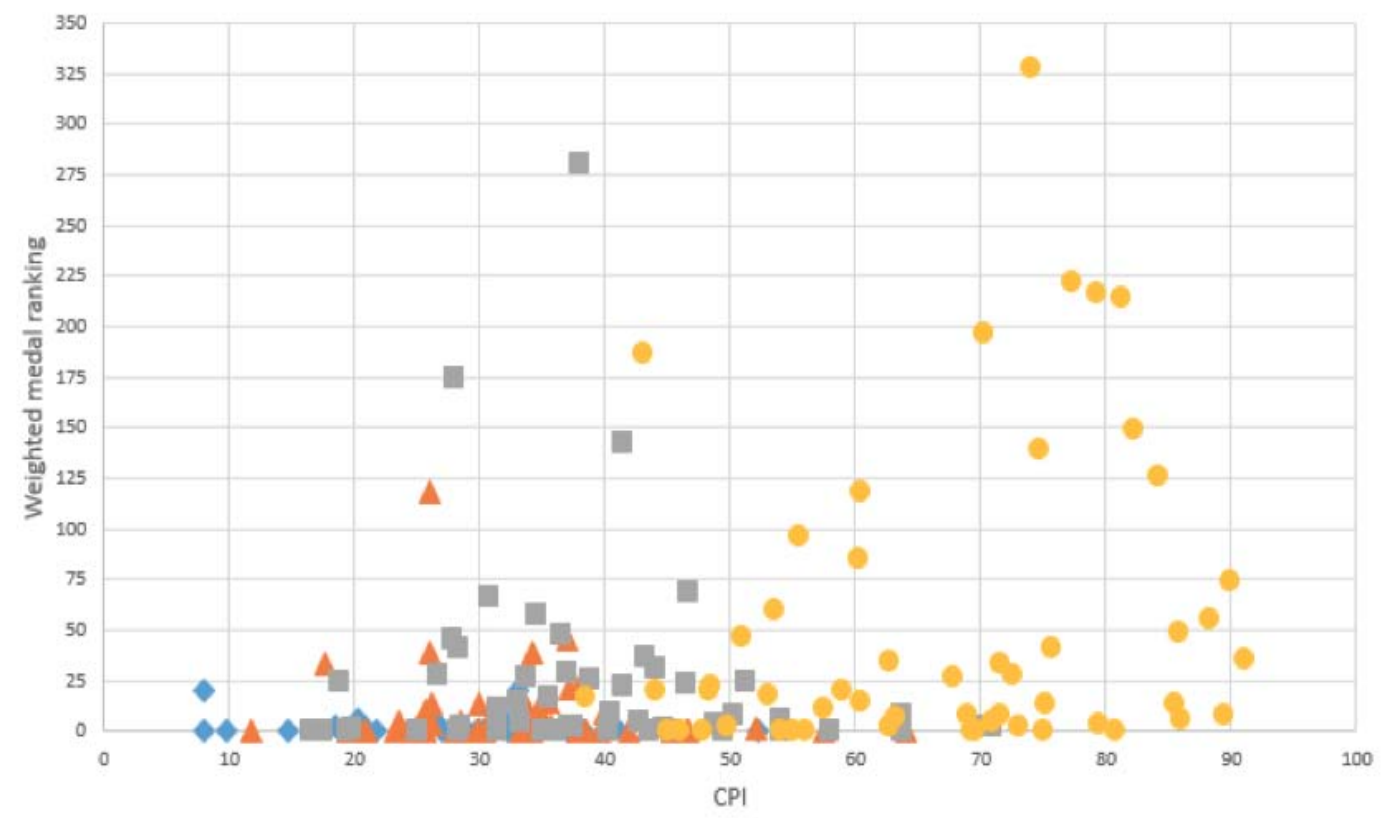

(own calculation)

This result is in contradiction to Potts (2014) who states that nations belonging to roughly the top quintile in control of corruption had a lower probability of achieving medals, and consequently receive lower medal shares. In this case, the control of corruption is analyzed using World governance indicators (such as population, GDP per capita, effect of host status country, level communism and climate). However, as Graycar (2015) pointed out, control and modification of corrupt behavior can ideally enhance public sector efficiency and performance. Corruption exists in both rich and poor countries and can appear in wide variety of areas (health service, education, etc.), as well as in sport (Masters, 2015). Improving corruption level would lead to higher public spending into these areas, and, consequently would lead to better sport performance (as in the case of Great Britain in Table 2). This conclusion goes along with our results, even though Ramírez and Sánchez (2013) did not prove statistical significance of corruption and its negative effect on GDP growth, in case of Mexico.

Finally, different variables for explaining the performance at Summer Olympics (regarding the weighted medal ranking) can be used. For example, Churilow and Flitman (2006) used DALE index (expressing health level of population) and IECS index (expressing index of equality of child survival) to analyze performance of participating countries at Sydney 2000 Olympic games. The idea behind this index is the healthier the population is, the easier is to find young athletes to perform at Olympics (EAP can serve as a variable with similar meaning). However, both parameters were not significant for explaining the performance at Sydney 2000 Olympic Games. Important parameters were, again, GDP per capita and total population (economic and demographic variables). This result goes along with our results. 


\section{Conclusion}

The main objective of the article was to analyze which economic, demographic and social indicators affect sport performance and summer Olympic game in Rio 2016. For this purpose, we used a set of 5 indicators: Gross domestic product, Economic active population, Corruption perception index, Gross national income, and Inflation rate. This set of indicators covers the most important economic and demographic indicators commonly used in sport performance analysis (GDP and EAP), as well as social indicators of CPI. The performance is represented by the weighted medal ranking, which includes first 8 positions from each discipline weighted using the IAAF methodology.

As the best explanatory model of the medal ranking can be supposed model (30) including GNI, CPI and EAP indicators. In this model, all parameters are statistically significant. Thus, the Olympic performance can be explained more complete than just by the classical population-GDP theory. In addition, the model has correct economic interpretation as all three parameters have positive coefficient. Therefore, growth in each of these parameters would result in better performance in Olympic Games. In detail, improving level of corruption by 1 point (considering Transparency International CPI index), would result in +2.476 weighted medal ranking, increase of EAP by $1 \%$ would result in gaining 4.29 in weighted medal ranking, and a change in GNI classification by one classification would result in a gain of 29.853 points in weighted medal ranking.

In this article, we have not included other economic, demographic or social factors, such as level of education, relation between sport performance and population health, as well as impacts of governmental policies on sport performance. Therefore, the future analysis will lead in this direction.

\section{Acknowledgement}

The authors would like to thank to La Salle University in México City, Mexico for the support in carrying out this work, which was done under university grant projects.

\section{References}

Boscá, Emilio, Vicente Liern, Aurelio Martínez and Ramón Sala. 2009. Increasing offensive or defensive efficiency? An analysis of Italian and Spanish football. Omega 37 (1): 63-78. http://dx.doi.org/10.1016/j.omega.2006.08.002

Carmichael, Fiona, Dennis Thomas, and Robert Ward. 2000. Team performance: the case of English premiership football. Managerial and Decision Economics 21(1): 31-45. http://dx.doi.org/10.1002/10991468(200001/02)21:1<31::AID-MDE963>3.3.CO;2-Q

Churilow, Leonid and Andy Flitman. 2006. Towards fair ranking of olympic achievements: the case of Sydney 2000. Computers and Operations Research, 33(7): 2057-2082. http://dx.doi.org/10.1016/j.cor.2004.09.027

Davis, Michael and Christian End. 2010. A winning proposition: The economic impact of successful National Football League franchises. Economic Inquiry, 48(1): 39-50. http://dx.doi.org/10.1111/j.14657295.2008.00124.x 
End, Christian, Beth Dietz-Uhler, Elizabeth Harrick and Lindy Jacquemotte. 2002. Identifying with winners: A reexamination of sport fans' tendency to BIRG. Journal of Applied Social Psychology, 32(5): 1017-1030. http://dx.doi.org/10.1111/j.1559-1816.2002.tb00253.x

Flegl, Martin. 2014. Performance analysis during the 2014 FIFA World Cup qualification. The Open Sports Science Journal, 7: 183-197. http://dx.doi.org/10.2174/1875399X01407010183

Flegl, Martin and Luis Andrade. 2016. Rio 2016 - Olympic Sport Economic Data. http://dx.doi.org/10.6084/ m9.figshare.4272200 (accessed November 30, 2016).

Gorse, Samantha and Simon Chadwick. 2011. The prevalence of corruption in international sport: A statistical analysis. Coventry: Centre for the International Business of Sport. Available at http://www.egba.eu/pdf/ Report-FINAL.pdf (accessed December 1, 2016).

Graycar, Adam. 2015. Corruption: Classification and analysis. Policy and Society, 34(2): 87-96. http://dx.doi. org/10.1016/j.polsoc.2015.04.001

Gujarati, Damodar and Dawn Porter. 2004. Basic econometrics. New York: Mc Graw Hill.

Li, Yongjun, Liang Liang, Yao Chen and Hiroshi Morita. 2008. Models for measuring and benchmarking olympics achievements. Omega, 36(6): 933-940. http://dx.doi.org/10.1016/j.omega.2007.05.003

Li, Yongjun, Xiyang Lei, Qianzhi Dai and Liang Liang. 2015. Performance evaluation of participating nations at the 2012 London Summer Olympics by a two-stage data envelopment analysis. European Journal of Operational Research, 243(3): 964-973. http://dx.doi.org/10.1016/j.ejor.2014.12.032

Lozano, Sebastián, Gabriel Villa, Fernando Guerrero and Pablo Cortés. 2002. Measuring the performance of nations at the Summer Olympics using data envelopment analysis. The Journal of the Operational Research Society, 53(5): 501-511. http://dx.doi.org/10.1057/palgrave/jors/2601327

Masters, Adam. 2015. Corruption in sport: From the playing field to the field of policy. Policy and Society, 34 (2): 111-123. http://dx.doi.org/10.1016/j.polsoc.2015.04.002

Müller, Martin. 2015. What makes an event a mega-event? Definitions and sizes. Leisure Studies 34 (6): 627642. http://dx.doi.org/10.1080/02614367.2014.993333

Potts, Todd. 2014. Governance, corruption and Olympic success. Applied Economics, 46 (31): 3882-3891. http://dx.doi.org/10.1080/00036846.2014.948672

Ramírez, Lucía and Isaac Sánchez. 2013. Crecimiento económico, corrupción e instituciones en México. Nóesis. Revista de Ciencias Sociales y Humanidades, 22 (43-1): 104-133. http://dx.doi.org/10.20983/noesis.2013.1.4 Rio. 2016. Rio 2016 - athletics schedule and results. Available at https://www.rio2016.com/en/athletics-schedule-and-results-download (accessed September 21, 2016).

Tiedemann, Torben, Tammo Francksen and Uwe Latacz-Lohmann. 2011. Assessing the performance of German Bundesliga football players: a non-parametric metafrontier approach. Central European Journal of Operations Research, 19(4): 571-587. http://dx.doi.org/10.1007/s10100-010-0146-7

Transparency International. 2016a. Corruption perception index. Available at http://www.transparency.org/ research/cpi/ (accessed October 10, 2016).

Transparency International. 2016b. Global corruption report: Sport. Routledge. ISBN: 978-1-315-69570-9. Available at http://www.transparency.org/news/feature/sport_integrity (accessed November 25, 2016).

Vagenas, George and Eleni Vlachokyriakou. 2012. Olympic medals and demo-economic factors: Novel predictors, the ex-host effect, the exact role of team size, and the "population-GDP" model revisited. Sport Management Review, 15(2): 211-217. http://dx.doi.org/10.1016/j.smr.2011.07.001 
- Revista de Ciencias Sociales y Humanidades. ISSN-P: 0188-9834 ISSN-E: 2395-8669.

World Bank. 2016. World Bank open data. World Bank. Available at http://data.worldbank.org/ (accessed October 15, 2016).

Wu, Jie, Liang Liang and Feng Yang. 2009. Achievement and benchmarking of countries at the Summer Olympics using cross efficiency evaluation method. European Journal of Operational Research, 197 (2): 722 730. http://dx.doi.org/10.1016/j.ejor.2008.06.030 